\title{
Chemical weathering and organic carbon turnover in soil
}

\author{
ERon R RAines ${ }^{1,2}$, Claire LuKENS $^{1}$, \\ KEVIN P NORTON ${ }^{1}$, ANTHONY DOSSETO ${ }^{2}$, \\ JuLIE DESLIPPE ${ }^{3}$, QUAN HuA ${ }^{4}$, JiE WANG ${ }^{5}$, \\ PETRIK GALOVOSAS ${ }^{5}$ AND MAIA BELLINGHAM ${ }^{1}$
}

${ }^{1}$ School of Geography, Earth, and Environmental Science, Victoria University of Wellington 6012, New Zealand;

${ }^{2}$ Wollongong Isotope Geochemistry Laboratory, School of Environment, Atmospheric, and Life Sciences, University of Wollongong, Wollongong 2522, Australia

${ }^{3}$ School of Biological Sciences, Victoria University of Wellington 6012, New Zealand

${ }^{4}$ Australian Nuclear Science and Technology Organisation, Kirrawee DC, NSW 2232, Australia

${ }^{5}$ School of Chemical and Physical Sciences, Victoria

University of Wellington 6012, New Zealand

*eron.raines@vuw.ac.nz

It is well accepted that secondary minerals, formed by chemical weathering, stabilize soil organic carbon (SOC). Little is known, however, about the relationship between the rates of SOC turnover, a biological process, and rates of chemical weathering. We investigated the dynamics of SOC turnover along one rapidly forming $(1.7 \mathrm{~mm} / \mathrm{year}) \mathrm{New}$ Zealand soil profile $(0-30 \mathrm{~cm})$ by combining U-series chronometry, geochemical analyses, radiocarbon dating, microbial ecology, and SOC chemical structure analysis.

Rates of chemical weathering should be restricted by rates of erosion at our study site. However, this was not the case thus providing a unique opportunity to explore the role of biogenic soil processes in facilitating weathering rates that exceed what, from a purely geological perspective, we might expect. Chemical weathering intensifies in our soil profile at $10 \mathrm{~cm}$. The ${ }^{14} \mathrm{C}$ content of bulk SOC decreased with depth and, typically, the ${ }^{14} \mathrm{C}$ content of chemically fractionated SOC pools followed the same trend. However, this trend was strongly disrupted at $10 \mathrm{~cm}$ where the bioavailable SOC pool pMC values were at their maxima and the passive SOC pool at a minima. This indicated that at $10 \mathrm{~cm}$, bioavailable carbon is rapidly turning over, or cycling. Where bioavailable carbon is rapidly cycling, the population of each microbial group within the soil is at a maximum and the chemical structure of bulk SOC has elevated O-alkyl content suggesting plant root inputs at and below $10 \mathrm{~cm}$ of fresh carbon.

Our results suggest that the shift in the intensity of carbon turnover rates indicates a potentially rapid, biologically driven flux of nutrients that is corroborated by an observed flux of elements from the soil at rates well above what the soil's mineralogy should allow. This suggests that biology may be facilitating intense chemical weathering where chemical weathering should otherwise be limited. 